\title{
Nonequivalent effects of PKC activation by PMA on murine CD4 and CD8 cell-surface
} expression

\author{
ERIC KALDJIAN, ${ }^{*}+1.1$ SUSAN A. MCCARTHY, ${ }^{\dagger .2}$ SUSAN O. SHARROW, ${ }^{\dagger}$ DAN R. LITTMAN, ${ }^{* .5}$ \\ RICHARD D. KLAUSNER, ${ }^{\ddagger}$ AND ALFRED SINGER ${ }^{\dagger}$ \\ *The Howard Hughes Medical Institute, Bethesda, Maryland 20817, USA; ${ }^{\dagger}$ Experimental Immunology Branch, \\ National Cancer Institute, National Institutes of Health, Bethesda, Maryland 20892, USA; ${ }^{\ddagger}$ Cell Biology and \\ Metabolism Branch, National Institute of Child Health and Human Development, National Institutes of Health, \\ Bethesda, Maryland 20892, USA; 'Department of Microbiology and Immunology, University of California, \\ San Francisce, Califormia 94143, USA
}

\begin{abstract}
The membrane glycoproteins CD4 (L3T4) and CD8 (Lyt2) are expressed on distinct populations of mature murine $\mathrm{T}$ lymphocytes, and are thought to be receptors for monomorphic determinants expressed on MHC class II and class I molecules, respectively. Although they differ in their ligand specificity, it has been presumed that CD4 and CD8 perform equivalent functions in the $\mathrm{T}$ cells that bear them. Since activation of protein kinase $\mathrm{C}$ (PKC) is known to cause rapid downregulation of various receptors, including the $T$ cell receptor complex (TcR complex), we treated cells with phorbol 12-myristate 13-acetate (PMA), a PKC activator, to determine whether cell-surface expression of CD4 and CD8 would be similarly affected by this intracellular mediator. Brief or relatively prolonged treatment with PMA induced mature murine $T$ cells to reduce their surface expression of the TcR complex and of CD4, but not of CD8. Similarly, PMA rapidly induced transfected $\mathrm{L}$ cells to down-regulate surface CD4 expression, but had no effect on surface CD8 expression. Most significantly, PMA treatment induced $\mathrm{CD}^{+} \mathrm{CD}^{+}$immature thymocytes to rapidly reduce their surface CD4 expression, but, again, it had no immediate effect on the surface expression of CD8. These results indicate that CD4 and TcR complex cell-surface expression are both sensitive to PKC activation by brief treatment with PMA, whereas CD8 expression is not, and suggest that CD4 and CD8 surface expression levels are regulated by distinct intracellular mechanisms. - KaLdJIAN, E.; McCarthy, S. A.; Sharrow, S. O.; Littman, D. R.; KLAUSNER, R. D.; Singer, A. Nonequivalent effects of PKS activation by PMA on murine CD4 and CD8 cell surface expression. FASEB J. 2: 2801-2806; 1988.
\end{abstract}

Key Words: CD4/CD8 accessory molecules - PMA-induced down-modulation $P K C$ activation - transfected $L$ cells double positive thymocytes
CD4 AND CD8 ARE MEMBRANE glycoproteins expressed on separate populations of peripheral murine $\mathrm{T}$ lymphocytes, and are thought to be functionally important in $\mathrm{T}$ cell activation. The $\mathrm{CD}^{+} \mathrm{CD8}^{-}$and $\mathrm{CD} 4^{-} \mathrm{CD}^{+}$ phenotypes correlate with $\mathrm{T}$ cell specificity: $\mathrm{CD4}^{+}$cells are restricted to $\mathrm{MHC}^{3}$ class II recognition, whereas $\mathrm{CD}^{+}$cells are predominantly restricted to recognition of MHC class I, and most $\mathrm{T}$ cell functions can be blocked by antibodies directed against CD4 or CD8 (1). These observations have led to two families of models of how CD4 and CD8 function. Avidity models postulate that CD4 and CD8 bind to MHC class II and class I molecules, respectively, to increase the avidity of the $T$ cell for antigen-bearing cells (1-4), although signaling models propose that CD4- and CD8-mediated signals regulate the signal transduced via the $T$ cell receptor (5-8). These two models are not necessarily mutually exclusive, and both imply that CD4 and CD8 may act as functional cell-surface receptors.

In several receptor signaling systems, engagement of the receptor triggers hydrolysis of polyphosphoinositides to phosphoinositols and diacyl glycerol (reviewed in ref 9). The diacyl glycerol produced by this reaction results in the activation of PKC, which (in addition to other intracellular events) may mediate cellular responses to extracellular stimuli. PKC activation can also lead to the down-regulation of a variety of surface receptors, possibly by phosphorylation of the receptors themselves. Activation of PKC directly by the diacyl glycerol analog PMA can mimic receptor-mediated signaling in these systems and cause phosphorylation, internalization, and down-regulation of surface receptors. For example, both murine $(10)$ and human $(11,12)$

\footnotetext{
'Present address: University of Michigan Medical School, Ann Arbor, MI 48109, USA.

${ }^{2}$ Correspondence should be addressed to Susan A. McCarthy, Bldg. 10, Room 4B-17, National Institutes of Health, Bethesda, MD 20892, USA.

${ }^{3}$ Abbreviations: MHC, major histocompatibility complex; MLC, mixed leukocyte culture; PKC, protein kinase C; PMA, phorbol 12-myristate 13-acetate; TcR complex, $T$ cell receptor complex.
} 
T cell receptor/T3 complex (TcR complex) components are known to respond to PMA by internalization and down-regulation of cell-surface expression.

Reduction of cell surface human CD4 (12-16) and murine thymic CD4 $(17,18)$ expression on exposure to PMA and related phorbol esters has also been reported. Most of those studies were complicated, however, by their relatively long time courses, and could reflect additional, later differentiative events induced by PMA. More recently, human CD4 $(16,19)$ and CD8 $(16,20)$ molecules have been shown to undergo rapid phosphorylation in response to brief PMA treatment, which suggests that these molecules are affected by PKC activation. In this study, we therefore compared the effects of brief and relatively prolonged PMA exposure on cell-surface expression of murine CD4 and CD8 on mature peripheral $T$ cells, immature thymic $T$ cells, and $L$ cell transfectants to determine whether expression of these $T$ cell differentiation antigens is regulated equivalently by PMA-induced PKC activation.

\section{MATERIALS AND METHODS}

Mice

C57BL/6J (B6), C57BL/10SnJ (B10), and DBA/2J mice were obtained from The Jackson Laboratory in Bar Harbor, Maine. B10 nu/nu (nude) mice were obtained from the Small Animal Section, National Institutes of Health (NIH) in Bethesda, MD.

\section{Antibodies}

53-6.72 rat anti-CD8 (anti-Lyt2) and 3.155 rat antiCD8 (anti-Lyt2) were obtained from the American Type Culture Collection (Rockville, MD). 53-5.83 rat anti-CD8 (anti-Lyt3) was provided by Dr. G. Nolan of Stanford University (Stanford, CA). GK1.5 rat anti-CD4 (anti-L3T4) was provided by Dr. F. Fitch, University of Chicago (Chicago, IL). RL-172/4 rat anti-CD4 (anti-L3T4) was provided by Dr. A. Kruisbeek, NIH. KJ16-113.18 rat anti-V $\beta 8 \mathrm{~T}$ cell receptor was provided by Drs. J. Kappler and P. Marrack of Denver, CO. 145-2C11 Armenian hamster anti-T3 (21) was a gift from Dr. J. Bluestone, NIH. 2.4G2 rat anti-Fc receptor was generously provided by Ms. J. Titus, NIH. FITC conjugates of 53-6.72 anti-CD8 and MAR 18.5 (mouse anti-rat kappa chain) antibodies were obtained from Becton Dickinson Immunocytometry Systems (Mountain View, CA). FITC-GAM (goat antimouse Ig) was from Boehringer Mannheim (Indianapolis, IN). FITC-20-8-4 anti-K ${ }^{\mathrm{b}}$, $\mathrm{Qa}$ was provided by Dr. D. Sachs, NIH, and was purified and conjugated in our laboratory. FITC-H129.19 and biotin-conjugated H129.19 anti-CD4 antibodies were the gifts of Ms. J. Titus. Texas red-conjugated streptavidin was from Bethesda Research Laboratories (Gaithersburg, MD).

Secondary mixed leukocyte culture (MLC) supernatant

Secondary MLC supernatant was the conditioned medium collected from a $\mathrm{B} 6$ anti-DBA/2J secondary sensitization culture after $24 \mathrm{~h}$, and was used in culture at a final concentration of $20-25 \%$.

\section{Enrichment and culture of $\mathrm{T}$ cells}

Spleen cells were passed over nylon wool and the nonadherent cells were collected and counted. For depletion of $\mathrm{CD}^{+}$cells, nylon wool nonadherent spleen cells were treated with RL-172/4 anti-CD4 $\mathrm{mAb}$ and rabbit C. $4 \times 10^{6}$ cells were cultured in $2 \mathrm{ml}$ of complete culture medium (RPMI 1640 plus $10 \%$ FCS) supplemented with secondary MLC supernatant. These cells were cultured overnight, harvested, and prepared for PMA treatment. Fresh thymocytes were prepared for use immediately before PMA treatment.

$\mathrm{L}$ cells

L cells transfected with genomic CD4 (L3T4) DNA (22) or genomic CD8 (Lyt2) DNA (23) have been reported previously.

\section{PMA treatment of cells}

A single cell suspension at $1 \times 10^{6} \mathrm{cells} / \mathrm{ml}$ was treated with 10 or $100 \mathrm{ng} / \mathrm{ml}$ PMA (Sigma, St. Louis, MO) for the indicated times at $37^{\circ} \mathrm{C}$ in $5 \% \mathrm{CO}_{2}$. Cells were immediately washed in cold-staining medium (HBSS without phenol red plus $0.1 \% \mathrm{BSA}$ and $0.1 \%$ sodium azide, $4^{\circ} \mathrm{C}$ ) and stained. PMA was stored at $-20^{\circ} \mathrm{C}$ in DMSO at $5 \mu \mathrm{g} / \mathrm{ml}$ or in ethanol at $100 \mu \mathrm{g} / \mathrm{ml}$. Control and experimental groups were handled identically except for PMA treatment. Cells treated with solvent alone at the same concentration as for PMA treatment had staining patterns identical to those of untreated cells (data not shown).

Antibody-induced down-modulation of CD4 and CD8

Cultures of 3-4 $\times 10^{6}$ nylon wool nonadherent B10 T cells and 1.5-2 $\times 10^{6} \mathrm{~B} 10$ nude spleen cells were established in $2.5 \mathrm{ml}$ culture medium (as above) containing $20 \%$ secondary MLC supernatant. Where indicated, GK1.5 anti-CD4 mAb or 53-6.72 anti-CD8 $\mathrm{mAb}$ was added to the cultures at a final concentration of $20 \%$. Cultures were incubated at $37^{\circ} \mathrm{C}$ in $7.5 \% \quad \mathrm{CO}_{2}$ for 3 days, when cells were harvested and prepared for flow cytometric analysis.

\section{Flow cytometry}

Cells were stained by standard procedures and analyzed for fluorescence intensity on a modified FACS II (Becton Dickinson Immunocytometry Systems, Mountain View, CA) (24). L cell and thymocyte stains were preceded by resuspension in $2.4 \mathrm{G} 2$ anti-Fc receptor $\mathrm{mAb}$ to reduce Fc-mediated nonspecific staining. Fluorescence data were collected using logarithmic amplification on 4-5 $\times 10^{4}$ viable cells, as determined by forward light scatter and propidium iodide exclusion. Amplification was provided by a 3-decade logarithmic amplifier con- 
structed from an NIH-modified design of R. Hiebert, Los Alamos Scientific Laboratories (Los Alamos, NM). For quantitative comparisons, median channel values of logarithmic fluorescence for positive subpopulations were converted to linear units with an empirically derived standard calibration curve. The effect of PMA treatment on fluorescence intensity was then defined as (linear units of PMA-treated cells - linear units of control cells)/linear units of control cells. Antibodies and staining reagents were used at concentrations previously shown to be saturating.

\section{RESULTS AND DISCUSSION}

To determine whether cell surface expression of the accessory molecules CD4 and CD8 is affected by PMAinduced PKC activation, B6 nylon wool-purified splenic $T$ cells were pulsed with PMA for 15 min, or left untreated, and then examined for cell-surface antigen expression by immunofluorescence and flow cytometry. As expected, cell surface expression of molecules in the TcR complex (T3 and TcR) was significantly reduced after 15-min exposure to PMA (Fig. 1, $C$ and D), whereas MHC class $I\left(H-2 K^{b}\right)$ expression was not (Fig. 1E). As with the TcR complex, CD4 surface expression was significantly reduced by PMA treatment (Fig. 1A); in contrast, CD8 surface expression was not reduced (Fig. $1 B$ ). Quantitative estimates of the alterations in cell surface expression of these molecules are presented in the figure legend.

A possible explanation for the dichotomy between the down-regulation of CD4 cell-surface expression and the lack of down-regulation of CD8 cell-surface expression after brief PMA treatment was that PMA had no effect on the expression of any cell-surface molecules on $\mathrm{CD8}^{+}$cells. To test this possibility, $\mathrm{CD}^{+}$-depleted splenic $\mathrm{T}$ cells (containing predominantly $\mathrm{CD}^{+} \mathrm{T}$ cells) were treated with PMA for $15 \mathrm{~min}$, or left untreated, and analyzed (Fig. 1, $F$ and $J$ ). These cells did exhibit down-regulation of their cell-surface TcR complex (Fig. 1, $H$ and $I$ ), but did not reduce their surface expression of CD8 (Fig. 1G). Therefore, mature $\mathrm{CD}^{+}$cells are responsive to the immediate effects of $\mathrm{PKC}$ activation by PMA, but cell-surface expression of CD8 molecules on these cells is not.

We therefore treated nylon wool-purified splenic $T$ cells with a higher concentration of PMA, over an extended time, to determine whether cell-surface expression of CD8 on mature $T$ cells could be regulated by PKC activation. Figure 2 illustrates that cell-surface CD8 expression, as measured by either anti-Lyt $2 \mathrm{mAb}$ (a different $\mathrm{mAb}$ than that used in Fig. 1) or anti-Lyt3 $\mathrm{mAb}$, was not reduced by PMA treatment (Fig. 2, $E-L)$. CD4 cell-surface expression, in contrast, was rapidly and progressively reduced by the same treatment (Fig. 2, $A-D$ ). These results, from a heterogeneous population of normal $\mathrm{T}$ cells, extend a similar observation based on a highly unusual $\mathrm{CD}^{+} \mathrm{CD}^{+}$ $T$ cell clone (16). Thus, prolongation of the PMA treatment did not eliminate the dichotomy in the regulation of CD4 and CD8 cell-surface expression on mature $T$ cells, but instead augmented it.

To further examine the responses of CD4 and CD8 to PMA-induced activation of PKC, $\mathrm{L}$ cell transfectants expressing either CD4 or CD8 were pulsed with PMA for $15 \mathrm{~min}$, or left untreated, and analyzed. We found that L cell-surface expression of CD4 was

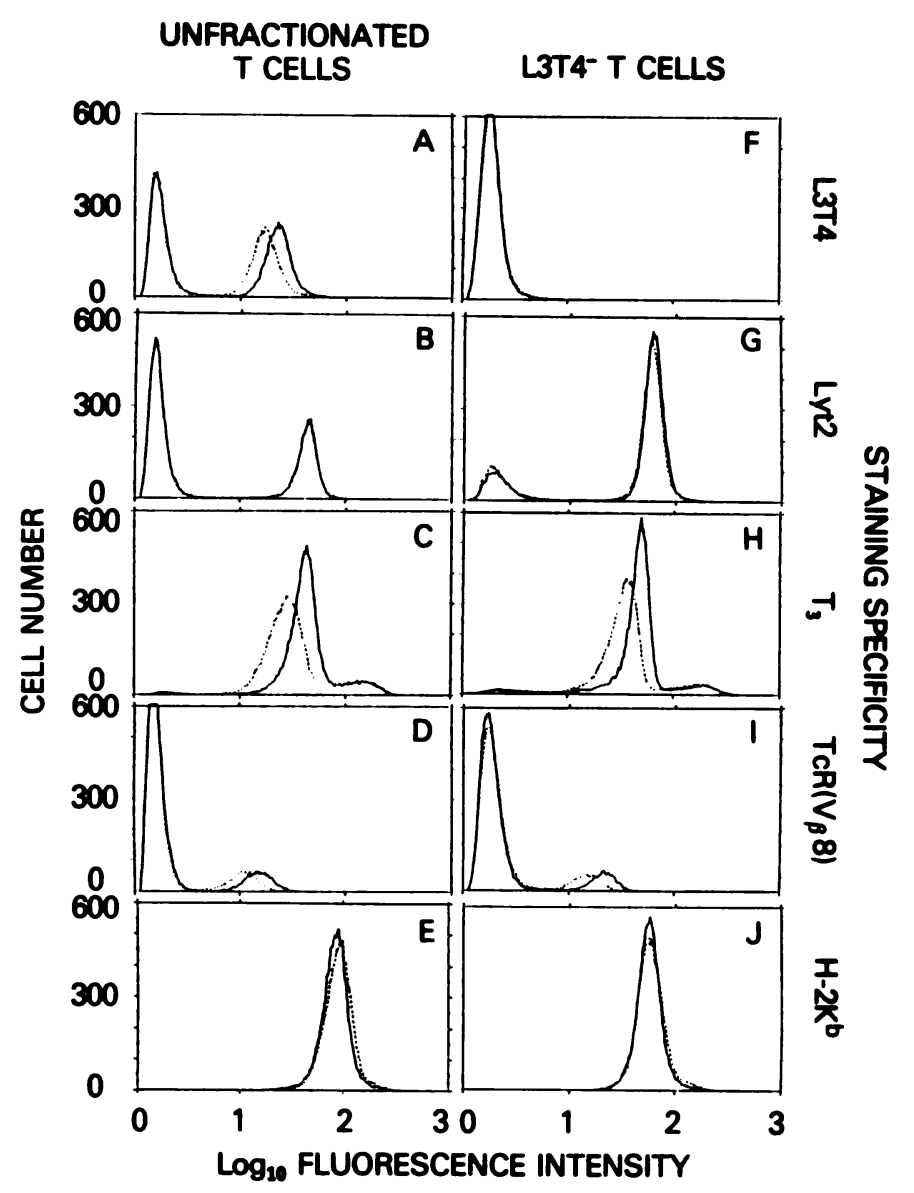

Figure 1. Brief PMA treatment causes down-regulation of CD4 but not CD8 cell-surface expression on mature splenic T cells. Nylonpurified B6 spleen cells $(A-E)$ or nylon-purified and CD4-depleted B6 spleen cells $(F-J)$ were cultured overnight in medium supplemented with secondary MLC supernatant. The cells were then collected, washed, counted, and pulsed with $10 \mathrm{ng} / \mathrm{ml}$ PMA, or left untreated, for $15 \mathrm{~min}$ at $37^{\circ} \mathrm{C}$. The cells were then washed and stained immediately with GK1.5 anti-CD4 (anti-L3T4) mAb and FITC-MAR $18.5(A$ and $F$ ), 53-6.72 anti-CD8 (anti-Lyt2) mAb and FITC-MAR 18.5 ( $B$ and $G$ ), 145-2C11 anti-T3 mAb and FITCGAM $(C$ and $H), \mathrm{KJ} 16$ anti-V $\beta 8 \mathrm{~T}$ cell receptor and FITC-MAR $18.5(D$ and $I)$, or FITC-20-8-4 anti-K ${ }^{\mathrm{b}}, \mathrm{Qa}(E$ and $J)$, and then analyzed by flow cytometry. Solid lines indicate untreated cells, dotted lines indicate PMA-treated cells. The quantitative effects of PMA treatment (see Materials and Methods) on fluorescence intensity in each panel (relative fluorescence of dotted lines to solid lines as measured by peak medians) are as follows: $A$ ) $-28 \%$; $B)+1 \% ; C)-37 \% ; D)-34 \% ; E)-4 \%$; $\left(F\right.$ shows $C^{2} 4^{+}$cell depletion); $G$ ) $-4 \%$; $H$ ) $-32 \% ; I)-37 \%$; and $J$ ) $+9 \%$. (The high fluorescence intensity shoulders in $C$ and $H$ were due to residual $B$ cells that were stained brightly by FITC-GAM alone, and were not included in quantitative analysis.) Freshly prepared (uncultured) nylon-purified spleen cells demonstrated the same dichotomy in the effects of brief PMA treatment on CD4 and CD8 cell-surface expression as did the cultured cells used here (data not shown). 
STANING SPECIFICITY

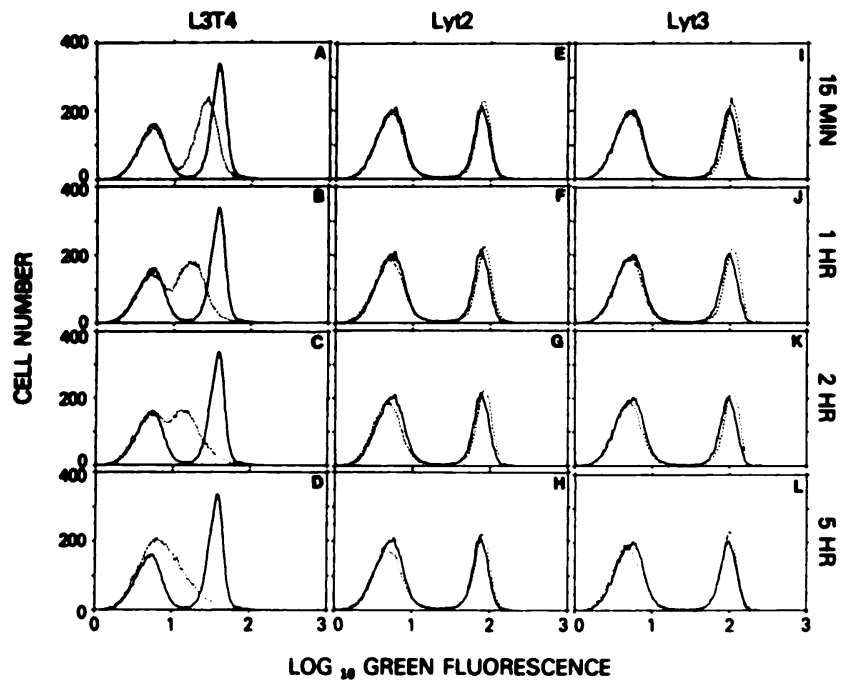

Figure 2. Kinetics of CD4 and CD8 cell-surface expression in response to PMA treatment. Nylon-purified B10 spleen cells were cultured overnight in medium supplemented with secondary MLC supernatant. The cells were then collected, washed, counted, and left untreated or pulsed with $100 \mathrm{ng} / \mathrm{ml}$ PMA for $15 \mathrm{~min}, 1,2$, or $5 \mathrm{~h}$ at $37^{\circ} \mathrm{C}$. The cells were then washed and stained immediately with RL-172/4 anti-CD4 (anti-L3T4) $\mathrm{mAb}$ and FITC-MAR 18.5 $(A-D), 3.155$ anti-CD8 (anti-Lyt2) $\mathrm{mAb}$, and FITC-MAR 18.5 $(E-H)$, or 53-5.83 anti-CD8 (anti-Lyt3) $\mathrm{mAb}$ and FITC-MAR 18.5 $(I-L)$ and then analyzed by flow cytometry. Solid lines indicate untreated cells; dotted lines indicate PMA-treated cells. The quantitative effects of PMA treatment on fluorescence intensity in each panel (relative fluorescence of dotted lines to solid lines as measured by peak medians) are as follows: $A$ ) $-39 \% ; B)-61 \%$; C) $-70 \%$; D) $-79 \% ; E)+7 \% ; F)+10 \% ; G)+12 \% ; H)+7 \% ; I)+11 \%$; $J)+14 \% ; K)+14 \%$, and $L)+3 \%$.

reduced in response to PMA, whereas $L$ cell surface expression of CD8 was not (Fig. 3). This result indicated that the effects of PMA on CD4 and CD8 surface expression levels in fibroblasts are similar to those in $\mathrm{T}$ cells. In addition, the ability of PMA to downregulate cell-surface expression of CD4 on L cells demonstrates that a physical and/or functional association of CD4 and the TcR complex, which has recently been proposed (25), is not required for down-regulation of CD4 surface expression in response to PKC activation.

The murine thymus contains a population of cells expressing both CD4 and CD8. We utilized two-color immunofluorescence and flow cytometry to examine the immediate and prolonged effects of PMA-induced PKC activation on cell-surface expression of CD4 and CD8 on such immature double positive cells. First, fresh thymocytes were pulsed with PMA for $15 \mathrm{~min}$ or left untreated, stained for CD4 in red and for CD8 in green, and analyzed. Figure 4 (a two-color flow cytometry plot) shows the effect of this PMA treatment on thymic-surface expression of CD4 and CD8. Single positive $\mathrm{CD4}^{+} \mathrm{CD8}^{-}$thymocytes responded to brief PMA treatment in the same way as did their mature splenic $T$ cell counterparts in that PKC activation reduced cell surface expression of CD4 (Fig. 4). Most important, after brief PMA treatment, double positive $\mathrm{CD}^{+} \mathrm{CD}^{+}$thymocytes also exhibited reduced surface CD4 expression, but had unaltered surface expression
L3T4+ L CELLS

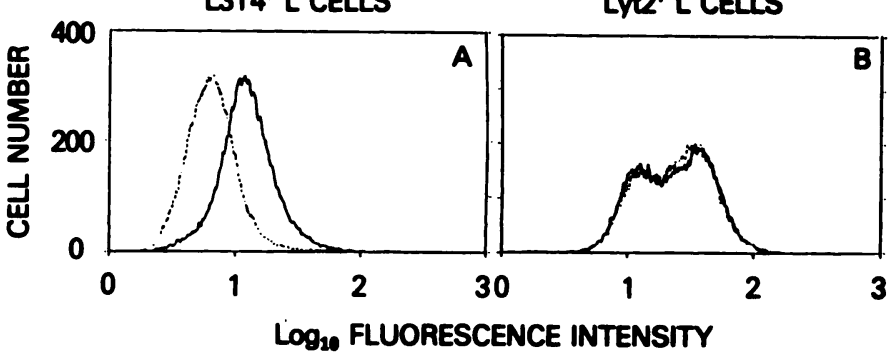

Figure 3. L cells transfected with CD4 (L3T4) DNA down-regulate CD4 cell-surface expression whereas L cells transfected with CD8 (Lyt2) DNA do not alter CD8 cell surface levels in response to brief PMA treatment. CD4- and CD8-transfected $L$ cells were pulsed with $100 \mathrm{ng} / \mathrm{ml} \mathrm{PMA}$, or left untreated, for $15 \mathrm{~min}$ at $37^{\circ} \mathrm{C}$, then immediately washed and stained. CD4-transfected L cells were stained with FITC-anti-CD4 $(A)$. CD8-transfected L cells were stained with FITC-anti-CD8 $(B)$. Solid lines indicate untreated cells; dotted lines indicate PMA-treated cells. The effects of PMA treatment on fluorescence intensity in each panel are as follows: A) $-67 \% ; B)+4 \%$.

of CD8 (Fig. 4). On prolonged exposure of thymocytes to PMA (Table 1), cell-surface expression of CD8 was marginally reduced, as has been previously reported (18). This reduction was exhibited by immature double positive thymocytes (data not shown), which represent the vast majority of the $\mathrm{CD}^{+}$cells in the thymus. The significant time lag before the onset of CD8 downregulation by these cells may reflect subsequent intracellular signals rather than PKC activation per se. In contrast, CD4 cell-surface expression underwent rapid and progressive reduction in response to $\mathrm{PKC}$ activation by PMA (Table 1). Inasmuch as CD4 and CD8 were

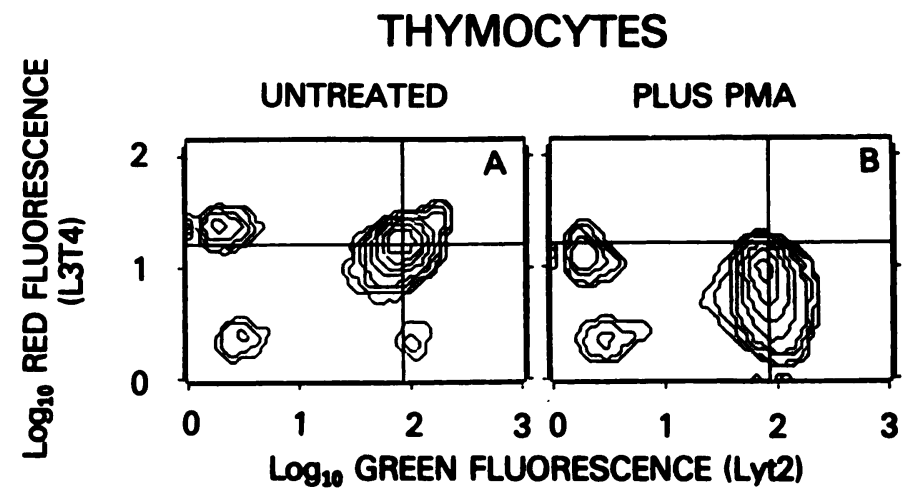

Figure 4. Brief PMA treatment causes down-regulation of CD4 but not CD8 cell-surface expression on $\mathrm{CD}^{+} \mathrm{CD} 8^{+}$. thymocytes. Fresh B10 thymocytes were pulsed with $100 \mathrm{ng} / \mathrm{ml}$ PMA $(B)$ or left untreated $(A)$ for $15 \mathrm{~min}$ at $37^{\circ} \mathrm{C}$, immediately washed and stained with FITC-anti-CD8 and biotin-anti-CD4 plus Texas red-avidin, and then analyzed by two-color flow cytometry. Two-color immunofluorescence data are plotted as increasing intensities of green (FITC) fluorescence vs. increasing intensities of red (Texas red) fluorescence. Constant values of total cell number were selected to draw the rings or contours around peaks of cells correlating green and red fluorescence. The perpendicular reference lines are intended as a visual aid and were drawn to intersect at the peak of the $\mathrm{CD}^{+} \mathrm{CD}^{+}$population of untreated thymocytes. Thymocytes treated with DMSO, the PMA solvent, at the same concentration as for PMA treatment, stained identically to untreated thymocytes (data not shown). 


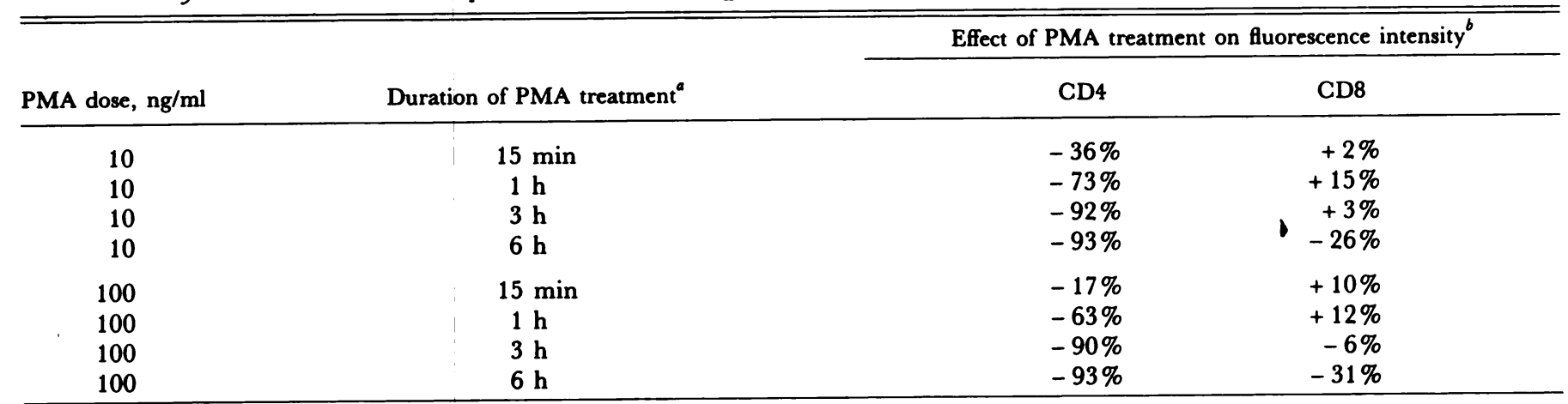

${ }^{a}$ Fresh $\mathrm{B} 6$ thymocytes were incubated for $6 \mathrm{~h}$ in medium. At the indicated times before the completion of the incubation, PMA was added. The cells were then stained and analyzed by flow cytometry as described in Materials and Methods. ${ }^{b}$ The quantitative effect of PMA treatment on CD4 and CD8 cell-surface expression was calculated as described in Materials and Methods.

coexpressed on the same cells in this population, the nonequivalent effects of PMA-induced PKC activation on CD4 and CD8 surface levels was a characteristic of the molecules themselves, and was not caused by differences in the response to PMA of the cells bearing these molecules.

Finally, we wished to rule out the possibility that CD8 molecules were inherently unable to undergo extensive reduction in surface expression by any means. Figure 5 shows that surface expression of CD8, as well as CD4, was dramatically reduced by antibody-mediated cross-linking. When nylon-purified splenic $T$ cells were cultured for 3 days with anti-CD4 or anti-CD8 antibody in the presence of B10 nude spleen cells, as a source of Fc receptor-bearing accessory cells to augment antibodymediated cross-linking, cell-surface expression of both CD8 and CD4, monitored by indirect staining, was markedly reduced.

One clearly described effect of PMA is the rapid activation of intracellular PKC (9). PKC, in turn, phosphorylates cytoplasmic residues and increases the endocytic internalization rates of many receptor molecules, which results in immediate reductions in the numbers of these molecules expressed on the cell surface $(10,11$,

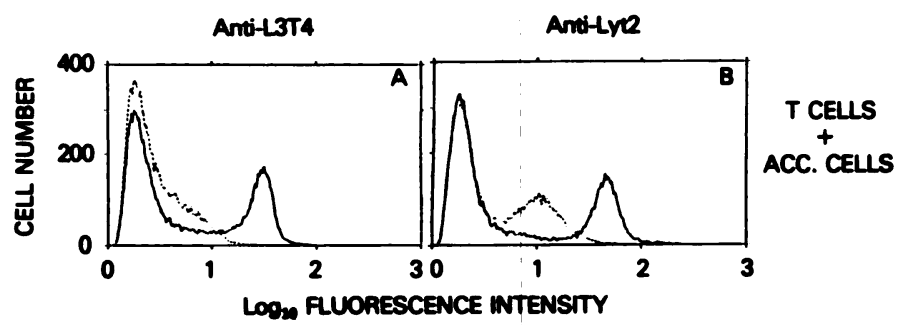

Figure 5. CD8 as well as CD4 cell-surface expression can be downregulated by antibody-mediated cross-linking. Nylon-purified B10 spleen cells were cultured for 3 days in medium supplemented with secondary MLC supernatant in the presence of B10 nude spleen cells with or without CK1.5 anti-CD4 $\mathrm{mAb}(A)$ and with or without 53-6.72 anti-CD8 mAb $(B)$. Cells were harvested, counted, and stained with GK1.5 mAb and FITC-MAR $18.5(A)$, or 53-6.72 $\mathrm{mAb}$ and FITC-MAR $18.5(B)$, and then analyzed by flow cytometry. Solid lines indicate cells cultured without $\mathrm{mAb}$; dotted lines indicate cells cultured with $\mathrm{mAb}$. The quantitative effects of antibody in culture on fluorescence intensity are as follows: $A$ ) $-87 \%$; B) $-82 \%$.
19). However, the relationship between phosphorylation and internalization of cell-surface receptor molecules is not obligatory (26-28), and, in fact, the effect of phorbol esters on receptor redistribution may be the result of the phosphorylation of nonreceptor elements involved in membrane trafficking. Indeed, PKC phosphorylates cytoplasmic residues on human CD4 $(16,19)$ and human CD8 (16, 20) molecules, and may phosphorylate cytoplasmic residues on both murine CD4 and CD8 as well. Thus, the present observation that PMA-induced activation of PKC rapidly down-regulates cell surface expression of murine CD4, but not murine CD8, was unexpected and is of special interest. The differential effects of prolonged PMA treatment on CD8 cellsurface expression in mature $\mathrm{CD}^{-} \mathrm{CD}^{+}$and immature $\mathrm{CD}^{+} \mathrm{CD}^{+} \mathrm{T}$ cells also merits further analysis.

Although PMA-induced PKC activation does not always mimic ligand engagement $(27,28)$, the striking disparity in the behavior of murine CD4 and CD8 on exposure to PMA in each experimental system we have studied indicates that the regulation of cell-surface expression of CD4 and CD8 molecules can be distinguished from each other. Consequently, this study raises questions about the presumption that CD4 and CD8 are functionally equivalent molecules that differ only in their ligand specificity.

We would like to thank Dr. Garry Nolan, Stanford University, Stanford, CA, for the generous gift of CD8-transfected L cells, David Stephany for expert assistance in flow cytometry, and Drs. Jeff Bluestone and Larry Samelson for critically reading the manuscript.

\section{REFERENCES}

1. Swain, S. T cell subsets and the recognition of $\mathrm{MHC}$ class. Immunol. Rev. 74: 129-142; 1983.

2. Biddison, W. E.; Rao, P. A.; Talle, M. A.; Goldstein, G.; Shaw, S. Possible involvement of the OKT4 molecule in $T$ cell recognition of class II HLA antigens. Evidence from studies of cytotoxic T lymphocytes specific for SB antigens. J. Exp. Med. 156: 1065-1076; 1982.

3. Meuer, S. C.; Schlossmann, S. F.; Reinherz, E. L. Surface structures involved in target recognition by 
human cytotoxic T lymphocytes. Science 218: 471473; 1982.

4. MacDonald, H. R.; Glasebrook, A. L.; Bron, C.; Kelso, A.; Cerottini, J.-C. Clonal heterogeneity in the functional requirement for Lyt-2/3 molecules on cytolytic T lymphocytes (CTL): possible implications for the affinity of CTL antigen receptors. Immunol. Rev. 68: 89-115; 1982.

5. Hunic, T. Monoclonal anti-Lyt-2.2 antibody blocks lectin-dependent cellular cytotoxicity of $\mathrm{H}-2$ negative target cells. J. Exp. Med. 159: 551-558; 1984.

6. Wassmer, P.; Chan, C.; Logdberg, L.; Shevach, E. M. Role of the L3T4 antigen in T cell activation. II. Inhibition of $\mathrm{T}$ cell activation by monoclonal antiL3T4 antibodies in the absence of accessory cells. J. Immunol. 135: 2237-2242; 1985.

7. Bank, I.; Chess, L. Perturbation of the T4 molecule transmits a negative signal to T cells. J. Exp. Med. 162: $1294-1303 ; 1985$

8. Tite, J.; Sloan, A.; Janeway, C., Jr. The role of L3T4 in T-cell activation: L3T4 may be both an Ia-binding protein and a receptor which transduces a negative signal. J. Mol. Cell. Immunol. 2: 179-190; 1986.

9. NishizukA, Y. Studies and perspectives of protein kinase C. Science 233: 305-312; 1986.

10. Minami, Y.; Samelson, L. E.; Klausner, R. D. Internalization and cycling of the $\mathrm{T}$ cell antigen receptor: role of protein kinase C. J. Biol. Chem. 262: 13342-13347; 1987.

11. Cantrell, D. A.; Davies, A. A.; Crumpton, M. J. Activators of protein kinase $\mathrm{C}$ down-regulate and phosphorylate the T3/T-cell antigen complex of human $\mathrm{T}$ lymphocytes. Proc. Natl. Acad. Sci. USA 82: 81588162; 1985.

12. Weyand, C. M.; Goronzy, J.; Fathman, C. G. Modulation of CD4 by antigenic activation. J. Immunol. 138: 1351-1354; 1987.

13. Solbach, W. Tumor promoting phorbol esters selectively abrogate the expression of the T4 differentiation antigen expressed on normal and malignant (Sezary) T helper lymphocytes. J. Exp. Med. 156: 1250$1255 ; 1982$.

14. Cassel, D. L.; Hoxie, J. A.; Cooper, R. A. Phorbol ester modulation of $\mathrm{T}$-cell antigens in the Jurkat lymphoblastic leukemia cell line. Cancer Res. 43: 45824586; 1983.

15. Hoxie, J. A.; Matthews, D. M.; Callahan, K. J.; Cassel, D. L.; Cooper, R. A. Transient modulation and internalization of $\mathrm{T} 4$ antigen induced by phorbol esters. J. Immunol. 137: 1194-1201; 1986.

16. Blue, M.-L.; Hafler, D. A.; Craig, K. A.; Levine, H.; Schlossman, S. F. Phosphorylation of CD4 and CD8 molecules following $\mathrm{T}$ cell triggering. J. Immunol. 139: 3949-3954; 1987.

17. Wang, P. T. H.; Bigby, M.; Sy, M.-S. Selective down modulation of L3T4 molecules on murine thymocytes by the tumor promotor, phorbol 12-myristate 13acetate. J. Immunol. 139: 2157-2165; 1987.

18. Havran, W. L.; Poenie, M.; Kimura, J.; Tsien, R.; Weiss, A.; Allison, J. P. Expression and function of the CD3-antigen receptor on murine $\mathrm{CD}^{+} 8^{+}$thymocytes. Nature (London) 330: 170-173; 1987.

19. Acres, R. B.; Conlon, P. J.; Mochizuki, D. Y.; Gallis, B. Rapid phosphorylation and modulation of the $T 4$ antigen on cloned helper $T$ cells induced by phorbol myristate acetate or antigen. J. Biol. Chem. 261: 16210-16214; 1986.

20. Acres, R. B.; Conlon, P. J.; Mochizuki, D. Y.; Gallis, B. Phosphorylation of the CD8 antigen on cytotoxic human $T$ cells in response to phorbol myristate acetate or antigen-presenting B cells. J. Immunol. 139: 2268-2274; 1987.

21. Leo, O.; Foo, M.; Sachs, D. H.; Samelson, L. E.; Bluestone, J. A. Identification of a monoclonal antibody specific for a murine T3 polypeptide. Proc. Natl. Acad. Sci. USA 84: 1374-1378; 1987.

22. Littman, D. R.; Getrner, S. N. Unusual intron in the immunoglobulin domain of the newly isolated murine CD4 (L3T4) gene. Nature (London) 325: 453455; 1987.

23. Tagawa, M.; Nakauchi, H.; Herzenberg, L. A.; Nolan, G. P. Formal proof that different-size Lyt-2 polypeptides arise from differential splicing and posttranscriptional regulation. Proc. Natl. Acad. Sci. USA 83: 3422-3426; 1986.

24. Segal, D. M.; Sharrow, S. O.; Jones, J. F.; SiragaNIAN, R. P. Fc(IgG) receptors on rat basophilic leukemia cells. J. Immunol. 126: 138-145; 1981.

25. Saizawa, K.; Rojo, J.; Janeway, C. A., Jr. Evidence for a physical association of CD4 and the CD3: $\alpha: \beta T$ cell receptor. Nature (London) 328: 260-263; 1987.

26. May, W. S.; Sahyoun, N.; Jacobs, S.; Wolf, M.; Cuatrecasas, P. Mechanism of phorbol diester-induced regulation of surface transferrin receptor involves the action of activated protein kinase $\mathbf{C}$ and an intact cytoskeleton. J. Biol. Chem. 260: 9419-9426; 1985.

27. Lin, C. R.; Chen, W. S.; Lazar, C. S.; Carpenter, C. D.; Gill, G. N.; Evans, R. M.; Rosenfeld, M. G. Protein kinase $C$ phosphorylation at Thr 654 of the unoccupied EGF receptor and EGF binding regulate functional receptor loss by independent mechanisms. Cell 44: 839-848; 1986.

28. Rothenberger, S.; Iacopetta, B. J.; Kuhn, L. C. Endocytosis of the transferrin receptor requires the cytoplasmic domain but not its phosphorylation site. Cell 49: 423-431; 1987.

Received for publication February 5, 1988. Accepted for publication May 8, 1988. 